\title{
AVALIAÇÃO DA SUSCETIBILIDADE À XYLELLA FASTIDIOSA EM DIFERENTES ESPÉCIES DE CAFEEIRO ${ }^{(1)}$
}

\author{
RACHEL BENETTI QUEIROZ-VOLTAN ${ }^{(2)}$; LUCIANE PEROSIN CABRAL ${ }^{(3)}$; \\ LUIZ CARLOS FAZUOLI ${ }^{(4 ; 5)}$; OSVALDO PARADELA FILHO ${ }^{(6)}$
}

\begin{abstract}
RESUMO
A bactéria Xylella fastidiosa Wells et al. foi detectada pela primeira vez em cafeeiro no Brasil, em 1995, entretanto acredita-se que a cultura foi infectada por essa bactéria há muitos anos, embora os sintomas fossem atribuídos a um estresse nutricional. Até o momento têm sido realizados estudos principalmente com espécies de C. arabica e C. canephora, porém, em outras espécies do gênero, somente foi detectada sua presença. Neste trabalho, objetivou-se avaliar a proporção de elementos de vaso do xilema obstruídos, total e parcialmente, pela X. fastidiosa, naturalmente infectadas, em diferentes espécies de cafeeiro do Banco de Germoplasma do IAC, visando identificar material resistente a essa bactéria para ser utilizado no programa de melhoramento genético. Os acessos estudados foram: C. canephora (progenitora da 'Guarini'), C. liberica var. liberica, os quatro acessos de C. liberica var. dewevrei (Ugandae, Dibowskii, Abeokutae, Excelsa) e o híbrido interespecífico Piatã (C. arabica X C. liberica var. dewevrei). Todos eles mostraram-se menos suscetíveis à X. fastidiosa. A porcentagem de obstrução dos elementos de vasos na folha não foi maior que $0,6 \%$ na maioria dos acessos, com exceção de Excelsa e do híbrido Piatã com até 2\% de obstrução, sendo bem menos suscetíveis a essa bactéria do que as cultivares de C. arabica. Trata-se, portanto, de materiais genéticos importantes para serem utilizados no programa de melhoramento do cafeeiro visando à resistência ao agente dessa doença.
\end{abstract}

Palavras-chave: Coffea, obstrução do xilema, bactéria.

\section{ABSTRACT \\ SUSCEPTIBITY VALUATION TO XYLELLA FASTIDIOSA IN DIFFERENT COFFEE SPECIES}

Xylella fastidiosa Wells et al. bacteria was firstly detected in coffee plants in Brazil in 1995. However it is believed to be attacking this crop this time. Disease symptoms have been attributed mostly to nutritional unbalances. Up to date studies have comprised only the species C. arabica and C. canephora. However X. fastidiosa was also detected in other Coffea species, but without disease symptoms. Aiming to identify in the IAC germoplasm collection resistant materials, the present study was under taken. The proportion of total or partial obstruction in xylem vessels of plants naturally infected with X. fastidiosa was evaluated in C. canephora ('Guarini' progenitor), C. liberica var. liberica, C. liberica var. dewevrei (Ugandae, Dibowskii, Abeokutae, and Excelsa) accesses and in the interespecific hybrid Piatã (C. arabica X C. liberica var. dewevrei). All tested materials showed to be less susceptible to X. fastidiosa. The obstruction percentage did not exceeded $0.6 \%$ except for "Excelsa" and the "Piatã" hybrid with about $2 \%$, even though both were much more resistant than C. arabica cultivars. All tested material is relevant to a coffee breeding program aiming at X. fastidiosa resistance.

Key words: Coffea, xylem obliteration, bacteria.

$\left({ }^{1}\right)$ Com recursos complementares do Consórcio Brasileiro de Pesquisa e Desenvolvimento do Café. Recebido para publicação em 26 de outubro de 2004 e aceito em 4 de agosto de 2005.

$\left({ }^{2}\right)$ Núcleo de Pesquisa e Desenvolvimento do Jardim Botânico/CEC/IAC/APTA/SAA, CP 28, 13001-970 Campinas (SP). E-mail: rachelqv@iac.sp.gov.br.

$\left({ }^{3}\right)$ Bolsista do Consórcio Brasileiro de Pesquisa e Desenvolvimento do Café.

$\left({ }^{4}\right)$ Centro de Análise e Pesquisa Tecnológica do Agronegócio do Café 'Alcides Carvalho', IAC.

$\left({ }^{5}\right)$ Com bolsa de produtividade em pesquisa do CNPq.

$\left({ }^{6}\right)$ Centro de Pesquisa e Desenvolvimento de Fitossanidade/IAC. Aposentado. 


\section{INTRODUÇÃO}

A bactéria Xylella fastidiosa Wells et al. foi detectada no Brasil pela primeira vez em cafeeiro por Paradela Filho et al. $(1995,1997)$. As plantas de café com sintomas externos da doença têm encurtamento dos entrenós, diminuição no comprimento dos pecíolos e na área foliar e senescência precoce das folhas mais maduras, resultando em um ramo com pequeno número de folhas no seu ápice. Devido ao encurtamento dos pedicelos e dos entrenós, as flores e os frutos ficam agrupados e têm, também, redução no seu tamanho (Paradela Filho et al. 1997; Queiroz-Voltan et al., 1998). Internamente, ocorre deposição de "goma" nos vasos do xilema, assim como divisões anormais no mesofilo e no xilema, floema e córtex do pecíolo e do caule de ramos com sintoma externo severos de infecção. As células do mesofilo das folhas de cafeeiro afetadas também têm número reduzido de cloroplastos, associado a maior concentração de cristais de oxalato de cálcio (QueIroz-Voltan et al., 1998).

Além do cafeeiro, essa bactéria causa doenças de importância econômica em diversas plantas cultivadas como alfafa e videira (GoHEEN et al., 1973); pessegueiro (Hopkins et al., 1973; NYLAND et al., 1973); amendoeira (Мircetich et al., 1976); ameixeira (Hopkins, 1989); citros (Chagas et al., 1992) e outras de menor interesse (Hopkins e ADLERZ, 1988). A grande maioria de hospedeiros naturais é assintomático e pertence a 28 famílias botânicas, incluindo mono e dicotiledôneas, (Hopkins e AdLERZ, 1988; Lopes et al., 1999) sendo, o vetor considerado como um polífago. São 39 espécies e 19 gêneros de Cicadellinae que tem sido descritos como vetores de X. fastidiosa. Desses, quatro espécies têm sido descritas como transmissoras de X. fastidiosa em cafeeiro: Bucephalogonia xanthophis (Berg.), Dilobopterus costalimai Young, Homalodisca ignorata Melichar e Oncometopia facialis (Signoret) (MARUCCI et al., 2001; PAIÃo et al., 2003)

Segundo Paradela FilHo et al. (1997) há muitos anos, o cafeeiro vem apresentando sintomas de infecção pela $X$. fastidiosa, que, entretanto, eram atribuídos a estresse nutricional devido a altas produções. Esses autores consideram que, no Brasil, a bactéria foi disseminada das plantas de cafeeiro para as laranjeiras devido à presença da bactéria em cafeeiro em regiões onde não havia plantações de citros, à presença da clorose variegada de citros em lavouras que sucederam a cultura cafeeira e à similaridade dos vetores transmissores dessa bactéria. REDAK et al. (2004) acreditam ainda que X. fastidiosa seja endêmica do continente americano por infectar diversas culturas exóticas, enquanto as nativas suportam a colonização da bactéria sem a presença dos sintomas.
Diversos trabalhos têm sido desenvolvidos em cafeeiro para o conhecimento da relação patógeno hospedeiro - vetor (Lima et al., 1996; QUEIROZ-Voltan, 1998, 2004a, b; 2005), entretanto, a maioria desses estudos tem sido realizada com cultivares de Coffea arabica L. e C. canephora Pierre ex A. Froehner.

Yorinori et al. (2003) detectaram a presença da $X$. fastidiosa em sete espécies e quatro híbridos interespecíficos de Coffea arabica, por meio do teste sorológico de DAS-ELISA e de imunoflorescência indireta, apesar da ausência de sintomas externos de infecção nessas plantas.

Até o momento, não existe nenhum controle químico contra a bactéria, porém, o manejo adequado da lavoura tende a reduzir os efeitos da Xylella nos cafeeiros. Pode-se considerar que essa bactéria está disseminada por todas as regiões cafeeiras do Estado de São Paulo e de outros Estados Brasileiros e, apesar do efeito e do prejuízo às lavouras não ter sido estimado, estudos sobre o controle dessa doença são essenciais para a cafeicultura.

O presente trabalho teve por objetivo avaliar a proporção de obstrução dos elementos de vaso do xilema, total e parcialmente, naturalmente infectados pela $X$. fastidiosa, em diferentes espécies de cafeeiro do Banco de Germoplasma do IAC, visando identificar material resistente à bactéria para ser utilizado no Programa de Melhoramento Genético.

\section{MATERIAL E MÉTODOS}

Os estudos foram efetuados em cafeeiros do Banco de Germoplasma do Centro de Análise e Pesquisa Tecnológica do Agronegócio do Café 'Alcides Carvalho'/IAC, localizado no Centro Experimental Central, Campinas (SP). Essa coleção tem aproximadamente 72 anos de idade e é conhecida como coleção de café "velha" de espécies de Coffea. A coleção está estabelecida em solo do tipo Latossolo Roxo, a uma latitude de $22^{\circ} 54^{\prime} 20^{\prime \prime} \mathrm{S}$, longitude de $47^{\circ} 05^{\prime} 34^{\prime \prime} \mathrm{W}$ e altitude de $674 \mathrm{~m}$, com as seguintes médias climáticas anuais: temperatura de $22,4{ }^{\circ} \mathrm{C}$, umidade relativa de $72,2 \%$ e precipitação pluvial de $1.430 \mathrm{~mm}$.

O estudo foi realizado com representantes de duas espécies de cafeeiro, Coffea liberica W. Bull ex Hiern e C. canephora (progenitoras da cultivar Guarini) (Herbário IAC sob n ${ }^{\circ} 38.462$ a 38.471) e de um híbrido F1 387, natural $(2 n=44)$ de Coffea arabica $\times$ Coffea liberica var. dewevrei, denominado Piatã (depositado no herbário IAC sob n 38.486 a 38.499). De C. liberica, trabalhou-se com a variedade liberica (depositado no 
herbário IAC sob n 38.472 a 38.485) e com quatro acessos de Coffea liberica var. dewevrei (De Wild. \& T. Durand) Lebrun, registrados na coleção com os nomes: C. dewevrei var. excelsa (Herbário IAC sob n: 38.390 a 38.401); C. dewevrei var. abeokutae (Herbário IAC sob n': 38.402 a 38.411); C. dewevrei var. dibowskii (Herbário IAC sob n': 38.412 a 38.421) e C. dewevrei var. ugandae (Herbário IAC sob nº 38.422 a 38.428).

A classificação botânica de C. liberica tem sido alterada pelos diferentes taxonomistas. LEBRUN (1941) propôs duas variedades para $C$. liberica: liberica e dewevrei. Chevalier (1947) considerava C. liberica, C. dewevrei e C. abeokutae como espécies distintas e, $C$. excelsa e C. dybowskii, como raças de $C$. dewevrei. BRIDSON (1988), com base nas espécies cultivadas da Região Leste da África, reconheceu as duas variedades de LEBRUN, embora não estivesse muito convencida, principalmente em relação ao caráter do disco floral. Em seu trabalho, BRIDSON (1988) discute que reconheceria Excelsa como uma forma da variedade Dewevrei, desde que Chevalier (1947) estivesse certo em dizer que Excelsa foi introduzida na agricultura a partir da República Africana Central. Na nomenclatura atual, as espécies C. abeokutae, C. dewevrei, C. excelsa e C. dibowskii passaram a ser sinonímias de C. liberica var. dewevrei.

Todas essas dúvidas decorreram da existência de poucos espécimes depositados nos herbários e também pelo fato de os cafeeiros Liberica e Excelsa passarem a ser cultivados pelo homem e a sua distribuição original natural obscurecida, dificultando aos taxonomistas a possibilidade de relacionar os caracteres taxonômicos e geográficos. A hibridização de formas cultivadas com formas nativas contribuiu também para o aumento dessas dificuldades taxonômicas, sendo necessários estudos multidisciplinares detalhados.

Os estudos quimiotaxonômicos realizados por LOPES E MONACO (1979) demonstraram alta afinidade dos flavonóides (86\%) entre Dewevrei e Liberica, reforçando a classificação de Lebrun (1941). Por outro lado, Lopes e Mônaco (1979) argumentaram que a afinidade diferencial com outras espécies também poderia justificar a separação entre Dewevrei e Liberica proposta por CHEVALIER (1947).

Neste trabalho, os acessos foram analisados separadamente porque se observam diferenças no grau de resistência a diversas doenças e pragas do cafeeiro (Medina-Filho et al., 1977, Guerreiro-Filho e MAZZAFERA, 2000, RAmiro et al., 2004) e, pretendeu-se verificar diferenças também na suscetibilidade à $X$. fastidiosa. A escolha desses materiais também foi feita devido à ausência de sintomas externos de infecção pela X. fastidiosa.

O cafeeiro Excelsa é considerado rústico, isto é, com alto vigor vegetativo e de produção elevada, porém com bebida de baixa qualidade, e um número somático de 22 cromossomos, o que dificulta a hibridização com o arábica, que possui 44 cromossomos (KRUG, 1950). Do mesmo modo, o Piatã tem alta produção, a rusticidade observada no Excelsa, porém, com 44 cromossomos, uma bebida considerada boa e autoestéril (KRUG, 1950). Todos esses materiais têm sido muito utilizados no programa de melhoramento visando à seleção de cafeeiros resistentes a doenças e pragas.

Doze plantas fizeram parte da amostra do híbrido e do acesso Excelsa, e cinco plantas nos demais acessos. Retiraram-se cinco ramos de cada planta de cada um dos sete acessos e desses ramos utilizaram-se cinco segmentos de $0,5 \mathrm{~cm}$ de comprimento do pecíolo e cinco de $0,25 \mathrm{~cm}^{2}$ do limbo de folhas adultas. Os segmentos do limbo foram retirados na região da nervura principal na porção mediana da folha e os do pecíolo foram retirados na região mediana. De C. liberica var. liberica e $C$. canephora retiraram-se também amostras do caule. Os segmentos do caule e das folhas foram retirados da região do ramo entre o $3 .^{\circ}$ ou $4 .^{\circ}$ nós. Esse estudo foi realizado apenas nas folhas e caule porque observouse que nesses órgãos havia maiores porcentagens dessa bactéria (Queiroz-Voltan et al. 2004a, 2005). Essas amostras foram fixadas em solução alcoólica etílica de formaldeído e ácido acético a 50\% (JohANSEn, 1940), incluídas em parafina e cortadas em micrótomo rotativo manual na espessura de 12 $\mathrm{mm}$ e coradas com safranina-alcian blue. A proporção entre o número de elementos de vaso do xilema obstruídos e o número observado foi obtida a partir de 50 campos amostrados dos segmentos dos órgãos, totalizando 250 estimativas dos acessos dos quais foram amostrados cinco indivíduos e 900 do híbrido e do acesso Excelsa dos quais foram amostrados doze indivíduos. A proporção foi estimada considerando-se o número de elementos de vaso que se apresentava total ou parcialmente obstruído por goma em relação ao número total de elementos de vaso por campo de área conhecida, com o auxílio de um microscópio óptico. A presença da bactéria nos elementos de vaso obstruídos foi confirmada através de microscopia ótica e microscopia eletrônica. Uma vez que a proporção de elementos de vaso obstruídos apresentava uma distribuição binomial, estimaram-se as médias e o desvio-padrão dos tratamentos, que foram comparados através de seus intervalos de confiança a 5\% de significância (SOKal e RoHlf, 1981). 
Avaliou-se o nível de obstrução das plantas com base em método estabelecido por QUEIROz-VOLTAN et al. (2005), obtido a partir da espécie C. arabica. Esse modelo estabelece cinco classes de obstrução: 1- sem obstrução; 2- pouco obstruído; 3- regularmente obstruído; 4- muito obstruído e 5- extremamente obstruído.

\section{RESULTADOS E DISCUSSÃO}

Os resultados da obstrução de elementos de vaso do xilema dos acessos estudados encontram-se nas tabelas 1 a 7 e, na Figura $1 \mathrm{~A}$ a G, pode-se observar a ausência de sintomas externos de infecção pela $X$. fastidiosa nas plantas.

Observou-se que todos os acessos se enquadraram na classe 2 de infecção determinadas a partir da espécie $C$. arabica, ou seja, pouco obstruídos pela $X$. fastidiosa. Embora as diferenças entre as proporções de obstrução dos elementos de vaso não tenham sido significativas entre as diferentes partes da planta, observou-se uma tendência do pecíolo ter uma obstrução maior, seguido da nervura principal do limbo e do caule. Resultados similares também foram obtidos por QUEIROZ-VOLTAN et al. (2004a, 2005) em cultivares de $C$. arabica e em videira por HOPKINS (1981). Na Figura 1I, pode-se observar apenas um elemento de vaso obstruído na secção transversal da nervura principal de Excelsa.

O desvio-padrão obtido da proporção de elementos de vaso obstruídos pela bactéria foi alto em todas as amostras. Observou-se que havia obstrução zero em uma porção da planta e logo acima, obstrução total e/ou parcial. Resultados semelhantes foram observados em cultivares de $C$. arabica por QUEIROZ-VOLTAN et al $(2004 a, 2005)$ e em videira por Hopkins (1981). Essa variação parece estar relacionada com o hábito alimentar do inseto vetor, ao deslocamento da bactéria na planta e à eficiência de transmissão da X. fastidiosa. Esses fatores são desconhecidos até o momento em cafeeiro (REDAK et al., 2004).

Tabela 1. Estimativas de obstrução de elementos de vaso do xilema de Coffea liberica do Banco de Germoplasma de cafeeiro do IAC, obtidas a partir de diferentes partes da planta $(n=5)$, infectadas por X. fastidiosa. Médias $(X)$, desvio-padrão (S) e intervalos de confiança (IC)

\begin{tabular}{|c|c|c|c|c|}
\hline Região & Planta & $x$ & S & IC \\
\hline \multirow[t]{5}{*}{ Caule } & 1 & 0,003 & 0,008 & $(-0,012 \leq \Pi \leq 0,018)$ \\
\hline & 2 & 0,000 & 0,000 & $(0,000 \leq \Pi \leq 0,000)$ \\
\hline & 3 & 0,000 & 0,000 & $(0,000 \leq \Pi \leq 0,000)$ \\
\hline & 4 & 0,000 & 0,000 & $(0,000 \leq \Pi \leq 0,000)$ \\
\hline & 5 & 0,000 & 0,000 & $(0,000 \leq \Pi \leq 0,000)$ \\
\hline Média total & & 0,001 & 0,004 & $(-0,002 \leq \Pi \leq 0,004)$ \\
\hline \multirow[t]{5}{*}{ Pecíolo } & 1 & 0,017 & 0,029 & $(-0,019 \leq п \leq 0,052)$ \\
\hline & 2 & 0,000 & 0,000 & $(0,000 \leq \Pi \leq 0,000)$ \\
\hline & 3 & 0,010 & 0,033 & $(-0,018 \leq \Pi \leq 0,039)$ \\
\hline & 4 & 0,000 & 0,000 & $(0,000 \leq \Pi \leq 0,000)$ \\
\hline & 5 & 0,002 & 0,012 & $(-0,011 \leq \Pi \leq 0,015)$ \\
\hline Média total & & 0,006 & 0,021 & $(-0,004 \leq$ п $\leq 0,015)$ \\
\hline Nervura & 1 & 0,007 & 0,017 & $(-0,016 \leq \Pi \leq 0,029)$ \\
\hline \multirow[t]{4}{*}{ Principal } & 2 & 0,000 & 0,000 & $(0,000 \leq \Pi \leq 0,000)$ \\
\hline & 3 & 0,003 & 0,010 & $(-0,012 \leq \Pi \leq 0,018)$ \\
\hline & 4 & 0,001 & 0,003 & $(-0,005 \leq п \leq 0,006)$ \\
\hline & 5 & 0,000 & 0,000 & $(0,000 \leq \Pi \leq 0,000)$ \\
\hline Média total & & 0,002 & 0,009 & $(-0,004 \leq \Pi \leq 0,008)$ \\
\hline
\end{tabular}


Tabela 2. Estimativas de obstrução de elementos de vaso do xilema do acesso Excelsa (C. liberica var. dewevrei) do Banco de Germoplasma de cafeeiro do IAC obtidas a partir de diferentes partes da planta $(\mathrm{n}=12)$, infectadas por X. fastidiosa. Médias $(X)$, desvio-padrão (S) e intervalos de confiança (IC)

\begin{tabular}{|c|c|c|c|c|}
\hline Região & Planta & $x$ & $S$ & IC \\
\hline & 1 & 0,014 & 0,037 & $(-0,013 \leq \pi \leq 0,040)$ \\
\hline & 2 & 0,033 & 0,101 & $(-0,008 \leq \Pi \leq 0,073)$ \\
\hline & 3 & 0,005 & 0,024 & $(-0,011 \leq$ п $\leq 0,021)$ \\
\hline & 4 & 0,011 & 0,020 & $(-0,013 \leq \pi \leq 0,034)$ \\
\hline & 5 & 0,048 & 0,098 & $(-0,001 \leq \Pi \leq 0,096)$ \\
\hline \multirow[t]{7}{*}{ Pecíolo } & 6 & 0,015 & 0,023 & $(-0,013 \leq \pi \leq 0,043)$ \\
\hline & 7 & 0,023 & 0,051 & $(-0,011 \leq \Pi \leq 0,057)$ \\
\hline & 8 & 0,020 & 0,039 & $(-0,012 \leq$ п $\leq 0,051)$ \\
\hline & 9 & 0,003 & 0,010 & $(-0,009 \leq \pi \leq 0,014)$ \\
\hline & 10 & 0,017 & 0,044 & $(-0,012 \leq \Pi \leq 0,047)$ \\
\hline & 11 & 0,034 & 0,056 & $(-0,007 \leq п \leq 0,074)$ \\
\hline & 12 & 0,013 & 0,030 & $(-0,013 \leq \pi \leq 0,039)$ \\
\hline \multirow[t]{6}{*}{ Média total } & & 0,020 & 0,053 & $(-0,011 \leq \pi \leq 0,029)$ \\
\hline & 1 & 0,006 & 0,020 & $(-0,012 \leq \Pi \leq 0,023)$ \\
\hline & 2 & 0,006 & 0,015 & $(-0,011 \leq \Pi \leq 0,023)$ \\
\hline & 3 & 0,006 & 0,018 & $(-0,011 \leq \Pi \leq 0,022)$ \\
\hline & 4 & 0,000 & 0,000 & $(0,000 \leq \pi \leq 0,000)$ \\
\hline & 5 & 0,003 & 0,012 & $(-0,009 \leq \pi \leq 0,015)$ \\
\hline Nervura & 6 & 0,004 & 0,015 & $(-0,010 \leq \Pi \leq 0,018)$ \\
\hline \multirow[t]{6}{*}{ Principal } & 7 & 0,006 & 0,026 & $(-0,011 \leq \Pi \leq 0,023)$ \\
\hline & 8 & 0,017 & 0,053 & $(-0,012 \leq \pi \leq 0,046)$ \\
\hline & 9 & 0,001 & 0,007 & $(-0,006 \leq \Pi \leq 0,008)$ \\
\hline & 10 & 0,001 & 0,006 & $(-0,006 \leq \pi \leq 0,008)$ \\
\hline & 11 & 0,004 & 0,012 & $(-0,010 \leq \pi \leq 0,018)$ \\
\hline & 12 & 0,003 & 0,009 & $(-0,010 \leq \pi \leq 0,016)$ \\
\hline Média total & & 0,005 & 0,021 & $(-0,001 \leq \Pi \leq 0,009)$ \\
\hline
\end{tabular}

Tabela 3. Estimativas de obstrução de elementos de vaso do xilema do acesso Ugandae (C. liberica var. dewevrei) do Banco de Germoplasma de cafeeiro do IAC obtidas a partir de diferentes partes da planta $(\mathrm{n}=5)$, infectadas por X. fastidiosa. Médias (X), desvio-padrão (S) e intervalos de confiança (IC)

\begin{tabular}{lcccc}
\hline Região & Planta & X & S & IC \\
\hline Pecíolo & 1 & 0,004 & 0,012 & $(-0,014 \leq \Pi \leq 0,022)$ \\
& 2 & 0,002 & 0,007 & $(-0,010 \leq \Pi \leq 0,014)$ \\
& 3 & 0,004 & 0,013 & $(-0,014 \leq \Pi \leq 0,022)$ \\
& 4 & 0,003 & 0,009 & $(-0,013 \leq \Pi \leq 0,019)$ \\
Média total & 5 & 0,004 & 0,013 & $(-0,013 \leq \Pi \leq 0,020)$ \\
Nervura & & 0,003 & 0,011 & $(-0,004 \leq \Pi \leq 0,011)$ \\
Principal & 1 & 0,000 & 0,000 & $(0,000 \leq \Pi \leq 0,000)$ \\
& 2 & 0,000 & 0,000 & $(-0,000 \leq \Pi \leq 0,000)$ \\
& 3 & 0,001 & 0,005 & $(-0,012 \leq \Pi \leq 0,013 \leq 0,011)$ \\
& 4 & 0,003 & 0,008 & $(0,000 \leq \Pi \leq 0,000)$ \\
Média total & 5 & 0,000 & 0,000 & $(-0,004 \leq \Pi \leq 0,011)$ \\
\hline
\end{tabular}


Tabela 4. Estimativas de obstrução de elementos de vaso do xilema do acesso Abeokutae (C. liberica var. dewevrei) do Banco de Germoplasma de cafeeiro do IAC obtidas a partir de diferentes partes da planta $(\mathrm{n}=5)$, infectadas por X. fastidiosa. Médias (X), desvio padrão (S) e intervalos de confiança (IC)

\begin{tabular}{lcccc}
\hline Região & Planta & X & S & IC \\
\hline Pecíolo & 1 & 0,008 & 0,016 & $(-0,003 \leq \Pi \leq 0,018)$ \\
& 2 & 0,001 & 0,000 & $(0,000 \leq \Pi \leq 0,000)$ \\
& 3 & 0,000 & 0,000 & $(0,000 \leq \Pi \leq 0,000)$ \\
& 4 & 0,001 & 0,006 & $(-0,003 \leq \Pi \leq 0,004)$ \\
Média total & 5 & 0,000 & 0,000 & $(0,000 \leq \Pi \leq 0,000)$ \\
Nervura & & 0,002 & 0,008 & $(-0,003 \leq \Pi \leq 0,007)$ \\
Principal & 1 & 0,007 & 0,006 & $(-0,004 \leq \Pi \leq 0,017)$ \\
& 2 & 0,001 & 0,000 & $(-0,003 \leq \Pi \leq 0,005)$ \\
& 3 & 0,000 & 0,006 & $(0,000 \leq \Pi \leq 0,000)$ \\
Média total & 4 & 0,001 & $(-0,003 \leq \Pi \leq 0,004)$ \\
& 5 & 0,000 & $(0,000 \leq \Pi \leq 0,000)$ \\
& & 0,002 & 0,009 & $(-0,003 \leq \Pi \leq 0,007)$ \\
\hline
\end{tabular}

Tabela 5. Estimativas de obstrução de elementos de vaso do xilema do acesso Dibowskii (C. liberica var. dewevrei) do Banco de Germoplasma de cafeeiro do IAC obtidas a partir de diferentes partes da planta $(\mathrm{n}=5)$, infectadas por X. fastidiosa. Médias (X), desvio-padrão (S) e intervalos de confiança (IC)

\begin{tabular}{lcccc}
\hline Região & Planta & $X$ & S & IC \\
\hline Pecíolo & 1 & 0,002 & 0,006 & $(-0,010 \leq \Pi \leq 0,013)$ \\
& 2 & 0,001 & 0,005 & $(-0,007 \leq \Pi \leq 0,009)$ \\
& 3 & 0,001 & 0,002 & $(-0,005 \leq \Pi \leq 0,005)$ \\
& 4 & 0,001 & 0,003 & $(-0,006 \leq \Pi \leq 0,008)$ \\
Média total & 5 & 0,009 & 0,031 & $(-0,017 \leq \Pi \leq 0,035)$ \\
Nervura & & 0,003 & 0,014 & $(-0,004 \leq \Pi \leq 0,009)$ \\
Principal & 1 & 0,000 & 0,000 & $(0,000 \leq \Pi \leq 0,000)$ \\
& 2 & 0,001 & 0,002 & $(-0,004 \leq \Pi \leq 0,004)$ \\
& 3 & 0,001 & 0,002 & $(-0,004 \leq \Pi \leq 0,004)$ \\
Média total & 4 & 0,001 & 0,003 & $(-0,006 \leq \Pi \leq 0,007)$ \\
& 5 & 0,001 & 0,003 & $(-0,006 \leq \Pi \leq 0,007)$ \\
& & 0,001 & 0,002 & $(-0,002 \leq \Pi \leq 0,002)$ \\
\hline
\end{tabular}

Quando todos os acessos estudados foram comparados, observou-se que embora tenha ocorrido sobreposição dos intervalos de confiança, havia uma tendência do pecíolo do acesso Excelsa (Tabela 2) e da folha (pecíolo e nervura principal) do Piatã (Tabela 6) serem mais obstruídos do que os demais. Considerando-se que esses dois acessos localizavamse nos dois extremos da coleção e estavam mais expostos às radiações solares do que os demais e que há maior severidade dos sintomas nos ramos de cafeeiro expostos aos raios solares poente, pode-se deduzir que a posição das plantas fosse a causa da maior obstrução. Entretanto, o fato de Piatã ser um híbrido de C. arabica, que é mais suscetível, parece explicar melhor a tendência desse acesso.
Em muitas plantas do acesso C. liberica não ocorreu infecção pela $X$. fastidiosa, principalmente da variedade Liberica (Tabela 1). Hopkins (1989) e PuRCEll e Hopkins (1996) discutiram que as diferenças encontradas entre plantas de mesmo genótipo poderiam ser atribuídas à distribuição não uniforme da bactéria nos órgãos da planta, isto é, normalmente as bactérias formam agregados que tendem a se acumular em partes específicas da planta. YORINORI et al. (2003), detectaram a presença da X. fastidiosa em todas as amostras de C. arabica, entretanto, nas demais espécies de Coffea, os resultados nem sempre foram positivos. Esses autores observaram que C. racemosa e C. dewevrei (sin. de C. liberica var. dewevrei) tinham menores proporções de amostras positivas a $X$. fastidiosa entre as espécies por eles estudadas. 
Tabela 6. Estimativas de obstrução de elementos de vaso do xilema do acesso Piatã (C. arabica x C. liberica var. dezvevrei) do Banco de Germoplasma de cafeeiro do IAC obtidas a partir de diferentes partes da planta (n=12), infectadas por X. fastidiosa. Médias (X), desvio-padrão (S) e intervalos de confiança (IC)

\begin{tabular}{|c|c|c|c|c|}
\hline Região & Planta & $x$ & $S$ & IC \\
\hline \multirow{12}{*}{ Pecíolo } & 1 & 0,017 & 0,039 & $(-0,012 \leq \pi \leq 0,047)$ \\
\hline & 2 & 0,030 & 0,064 & $(-0,009 \leq \pi \leq 0,069)$ \\
\hline & 3 & 0,016 & 0,043 & $(-0,012 \leq \pi \leq 0,045)$ \\
\hline & 4 & 0,000 & 0,000 & $(0,000 \leq \pi \leq 0,000)$ \\
\hline & 5 & 0,030 & 0,034 & $(-0,009 \leq \pi \leq 0,068)$ \\
\hline & 6 & 0,030 & 0,037 & $(-0,009 \leq \pi \leq 0,068)$ \\
\hline & 7 & 0,023 & 0,047 & $(-0,011 \leq \pi \leq 0,056)$ \\
\hline & 8 & 0,030 & 0,053 & $(-0,009 \leq \pi \leq 0,068)$ \\
\hline & 9 & 0,016 & 0,045 & $(-0,012 \leq \pi \leq 0,044)$ \\
\hline & 10 & 0,042 & 0,048 & $(-0,004 \leq \pi \leq 0,087)$ \\
\hline & 11 & 0,021 & 0,044 & $(-0,011 \leq \pi \leq 0,054)$ \\
\hline & 2 & 0,001 & 0,003 & $(-0,004 \leq \pi \leq 0,004)$ \\
\hline \multirow{6}{*}{ Média total } & - & 0,021 & 0,043 & $(-0,012 \leq \pi \leq 0,031)$ \\
\hline & 1 & 0,016 & 0,027 & $(-0,012 \leq n \leq 0,045)$ \\
\hline & 2 & 0,006 & 0,030 & $(-0,011 \leq \pi \leq 0,023)$ \\
\hline & 3 & 0,019 & 0,027 & $(-0,012 \leq \pi \leq 0,049)$ \\
\hline & 4 & 0,001 & 0,005 & $(0,006 \leq \pi \leq 0,008)$ \\
\hline & 5 & 0,035 & 0,031 & $(-0,006 \leq \pi \leq 0,077)$ \\
\hline Nervura & 6 & 0,040 & 0,044 & $(-0,004 \leq \pi \leq 0,085)$ \\
\hline \multirow[t]{6}{*}{ Principal } & 7 & 0,013 & 0,032 & $(-0,013 \leq \pi \leq 0,039)$ \\
\hline & 8 & 0,042 & 0,065 & $(-0,004 \leq \pi \leq 0,087)$ \\
\hline & 9 & 0,025 & 0,061 & $(-0,010 \leq \pi \leq 0,061)$ \\
\hline & 10 & 0,080 & 0,077 & $(-0,018 \leq \pi \leq 0,141)$ \\
\hline & 11 & 0,023 & 0,039 & $(-0,011 \leq \pi \leq 0,057)$ \\
\hline & 12 & 0,002 & 0,008 & $(-0,009 \leq \pi \leq 0,013)$ \\
\hline Média total & & 0,025 & 0,047 & $(-0,015 \leq \pi \leq 0,035)$ \\
\hline
\end{tabular}

Tabela 7. Estimativas de obstrução de elementos de vaso do xilema de Coffea canephora var. guarini do Banco de Germoplasma de cafeeiro do IAC, obtidas a partir de diferentes partes da planta $(\mathrm{n}=5)$, infectadas por X. fastidiosa. Médias (X), desvio-padrão (S) e intervalos de confiança (IC)

\begin{tabular}{lcccc}
\hline Região & Planta & X & S & IC \\
\hline Caule & 1 & 0,004 & 0,011 & $(-0,014 \leq \Pi \leq 0,022)$ \\
& 2 & 0,000 & 0,000 & $(0,000 \leq \Pi \leq 0,000)$ \\
& 3 & 0,001 & 0,001 & $(-0,004 \leq \Pi \leq 0,004)$ \\
& 4 & 0,000 & 0,000 & $(-0,000 \leq \Pi \leq 0,000)$ \\
Média total & 5 & 0,003 & 0,009 & $(-0,003 \leq \Pi \leq 0,016)$ \\
Pecíolo & & 0,001 & 0,007 & $(0,003 \leq \Pi \leq 0,150)$ \\
& 1 & 0,030 & 0,054 & $(-0,018 \leq \Pi \leq 0,038)$ \\
& 2 & 0,001 & 0,005 & $(-0,019 \leq \Pi \leq 0,053)$ \\
& 3 & 0,013 & $(-0,014 \leq \Pi \leq 0,097)$ \\
Média total & 4 & 0,031 & $(-0,019 \leq \Pi \leq 0,063)$ \\
Nervura & 5 & 0,012 & 0,013 & $(-0,002 \leq \Pi \leq 0,022)$ \\
Principal & & 0,004 & 0,031 & $(-0,018 \leq \Pi \leq 0,037)$ \\
& 1 & 0,010 & 0,016 & $(-0,014 \leq \Pi \leq 0,022)$ \\
& 2 & 0,010 & 0,013 & $(-0,013 \leq \Pi \leq 0,020)$ \\
Média total & 3 & 0,004 & 0,027 & $(-0,019 \leq \Pi \leq 0,046)$ \\
& 4 & 0,004 & 0,008 & $(-0,008 \leq \Pi \leq 0,010)$ \\
& 5 & 0,014 & 0,019 & $(-0,004 \leq \Pi \leq 0,016)$ \\
\hline
\end{tabular}



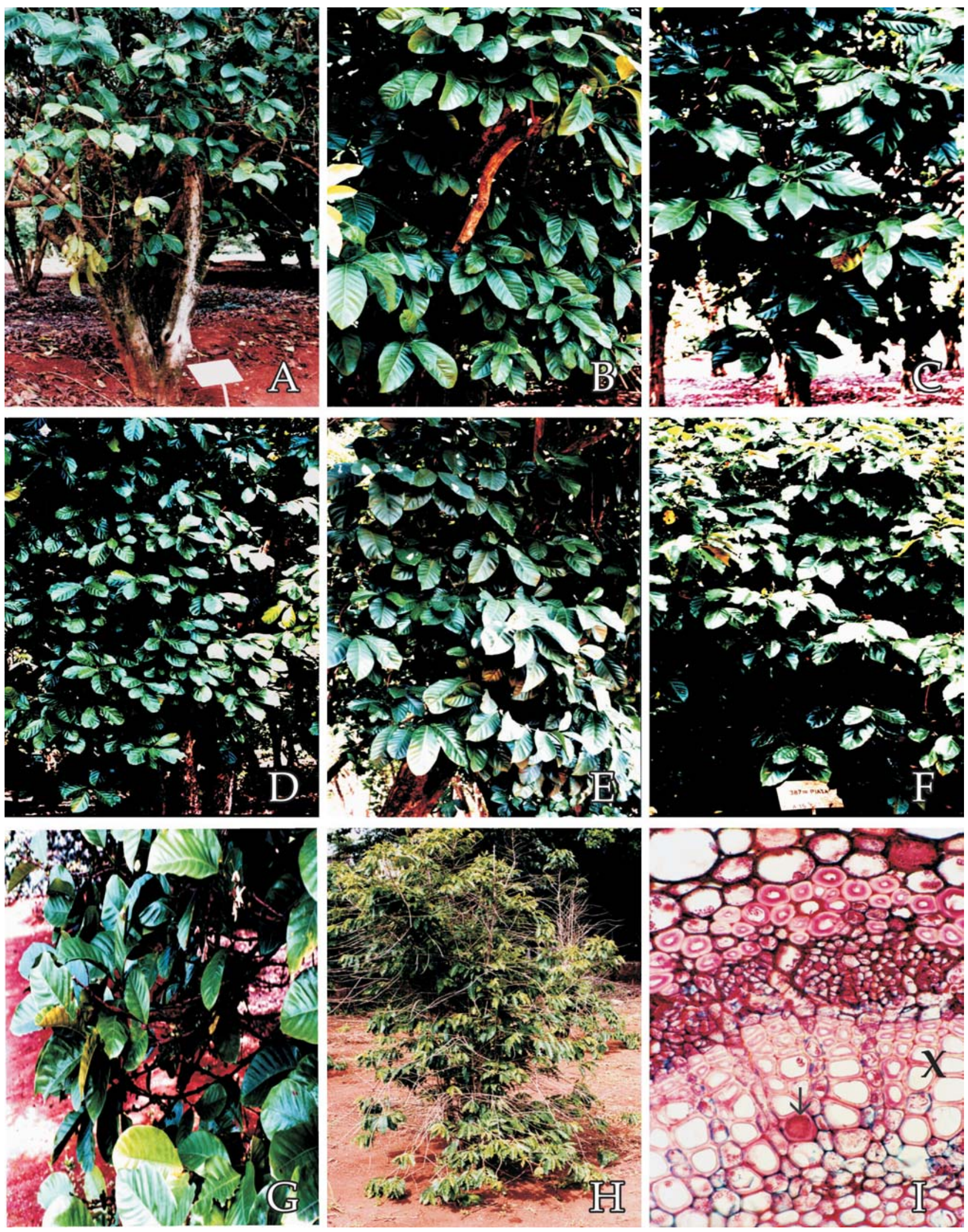

Figura 1. Acessos do Banco de Germoplasma de cafeeiro do IAC: A- Coffea liberica; B- Excelsa (C. liberica var. dezvevrei); C- Ugandae (C. liberica var. dewevrei); D- Abeokutae (C. liberica var. dewevrei); E- Dybowskii (C. liberica var. dewevrei); F- Piatã (C. liberica var. dewevrei); G- C. canephora (progenitor da Guarini); H- C. arábica var. typica; I- Corte transversal de nervura principal de Excelsa. $F$ = Floema; $X$ = Xilema. A seta indica elemento de vaso do xilema obstruído. 
O fato de as plantas dessa coleção estarem expostas aos vetores da $X$. fastidiosa há muitos anos, supõe-se que, muito provavelmente, foram encontradas por esses vetores que não mostraram preferência por tecidos mais tenros que as arábicas ou ainda, sugere-se que possam haver diferenças na composição química das plantas, como tem sido descrito por outros autores (MedinA-FilHo et al., 1977, Guerreiro-Filho E Mazzafera, 2000, Ramiro et al., 2004), que poderiam não ser favoráveis ao estabelecimento da bactéria ou para a escolha alimentar de seus vetores.

No pecíolo do acesso Excelsa, região da planta que comumente é mais colonizada pela bactéria (Queiroz-Voltan et al., 2004a), observou-se tendência maior na obstrução dos elementos de vaso do xilema em comparação aos outros três acessos de Coffea liberica var. dewevrei: Abeokutae, Ugandae e Dibowskii.

Todos os acessos estudados foram pouco infectados pela X. fastidiosa em relação a C. arabica, se considerar que a porcentagem de obstrução dos elementos de vasos do pecíolo na maioria dessas espécies não foi maior que $0,6 \%$, com exceção de Excelsa e do híbrido Piatã, com até $2 \%$ de obstrução dos elementos de vasos. Em C. arabica observaram-se até $8 \%$ de vasos obstruídos no pecíolo, local onde a obstrução dos vasos é geralmente maior (QueIrozVoltAn et al., 2004a, 2005).

Os mecanismos de resistência em cafeeiro não são ainda conhecidos, mas observou-se que cafeeiros vizinhos de C. arabica var. typica estavam com sintomas típicos da doença (Figura $1 \mathrm{H}$ ), bem como das cultivares Catuaí e Mundo Novo cultivadas próximas a essa coleção estavam infectadas por essa bactéria (Queiroz-Voltan et al., 1998). Nas plantas estudadas não ocorreram sintomas externos típicos da presença da bactéria, indicando baixa suscetibilidade a esse patógeno.

\section{CONCLUSÃO}

Em C. canephora, genitora da cultivar Guarini, C. liberica var. liberica, os quatro acessos de C. liberica var. dewevrei (Ugandae, Dibowskii, Abeokutae, Excelsa) e o híbrido interespecífico Piatã (C. arabica X C. liberica var. dewevrei) do Banco de germoplasma de cafeeiro do IAC houve pouca infecção pela Xylella fastidiosa, sendo menos suscetível a essa bactéria do que as cultivares de $C$. arabica. Trata-se, portanto, de materiais genéticos importantes para serem utilizados no programa de melhoramento do cafeeiro visando à resistência ao agente dessa doença.

\section{AGRADECIMENTOS}

Ao Pesquisador Científico aposentado do IAC, Armando Conagin, pela orientação nas análises estatísticas.

\section{REFERÊNCIAS}

BRIDSON, D.; VERDCOURT, B. Rubiaceae (Part 2). In: POLHILL, R. M. (Ed.). Flora of Tropical East Africa. Kew: 1988. p.703-722.

CHAGAS, C.M.; ROSSETTI, V.; BERETTA, M.J.G. Electron microscopy studies of xylem-limited bacterium in sweetorange affected with Citrus variegated chlorosis disease in Brazil. Journal of Phytopathology, Berlin, v.34, p.306312, 1992.

CHEVALIER, A. Systématique des caféiers et faux-caféiers maladies et insectes nuisibles. In: Lechevalier, P. (Ed.). Les Caféiers du globe. Fasc. III. Paris: Editora, 1947. 356p.

GOHEEN, A.C.; NYLAND, G. \& LOWE, S.K. Association of a rickettsia-like organism with Pierce's disease of grapevines and alfalfa dwarf and heat therapy of the disease in grapevines. Phytopathology, St. Paul, v.63, p.341-345, 1973.

GUERREIRO-FILHO,O.; MAZZAFERA, P. Caffeine does not protect coffee against the leaf miner, Perileucoptera coffeella. Journal of Chemical Ecology, New York, v.26, n.6, p.1447$1464,2000$.

HOPKINS, D.L. Seasonal concentration of the Pierce's disease bacterium in grapevine stems, petioles and leaf veins. Phytopathology, St. Paul, v.71, p.415-418, 1981.

HOPKINS, D.L. Xylella fastidiosa: xylem-limited bacterial pathogen of plants. Annual Review Phytopathology, Palo Alto, v.27, p.271-290, 1989.

HOPKINS, D.L.; ADLERZ, W.C. Natural hosts of Xylella fastidiosa in Florida. Plant Disease, St. Paul, v.72, p.429-431, 1988.

HOPKINS, D.L.; MOLLENHAUER, H.A.; FRENCH, W.J. Occurrence of a rickettsia-like bacterium in the xylem of peach trees with phony disease. Phytopathology, St. Paul, v.63, p.1422-1423, 1973.

JOHANSEN, D.A. Plant microtechnique. New York: McGrawHill, 1940. 523p.

LEBRUN, J. Recherches morphologiques et systématiques sur les caféiers du Congo. Bruxelas: I.N.É.A.C. (Instituto Nacional para o estudo agronômico do Congo Belga), 1941, 183p.

LIMA, J.E.O.; MIRANDA, V.S.; HARTUNG, J.S.; BRLANSKY, R.H.; COUTINHO, A.; ROBERTO, S.R.; CARLOS, E.F. Distribuição da Xylella fastidiosa no cafeeiro, nas regiões cafeeiras e seu isolamento "in vitro". Fitopatologia Brasileira, Brasília, v. 21, n.3, p.392-393, 1996. 
LOPES, C.R.; MONACO, L.C. Chemotaxonomic studies of some species of the genus Coffea. Journal of Plantation Crops, v.7, n.1, p.6-14, 1979.

LOPES, A.S.; ROBERTO, G.P.; FRANÇA, S.C. Hospedeiros alternativos de Xylella fastidiosa dos citros. Fitopatologia Brasileira, Brasília, v.24, p.250 (Supl.), 1999.

KRUG, C.A. Uma nova forma de Coffea. Bragantia, Campinas, v.10,n.1, p.11-25, 1950.

MARUCCI, R.C.; GIUSTOLIN, T.A.; MIRANDA, M.P.; FERRAZ, P.C.; LOPES, J.R.S. Transmissão de Xylella fastidiosa para café pela cigarrinha Dilobopterus costalimai. . In: II SIMPÓSIO DE PESQUISA DOS CAFÉS DO BRASIL, Vitória, 2001. Anais... Brasília: Consórcio Brasileiro de Pesquisa e Desenvolvimento do Café, 2001. v.1, p.1220-1227.

MEDINA-FILHO, H.P.; CARVALHO, A.; MONACO, L.C. Melhoramento do cafeeiro. XXXVII. Observações sobre a reistência do cafeeiro ao bicho mineiro. Bragantia, Campinas, v.36, p.131-137, 1977.

MIRCETICH, S.M.; LOWE, S.K.; MOLLER, W.J.; NYLAND, G. Etiology of almond leaf scorch disease and transmission of the causal agent. Phytopathology, St. Paul, v.66, p.17-24, 1976.

NYLAND, G.; GOHEEN, A.C.; LOWE, S.K.; KIRKPATRICK, H.C. The ultrastructure of a rickettsia-like organism from a peach tree affected with phony disease. Phytopathology, St. Paul, v.63, p.1255-1258, 1973.

PAIÃO, F.G.; NOVAES, T.G. de; ROSSINI, V.; MOTOMURA, K.F.; LOVATO, L.; MENEGUIM, A.M.; LEITE JÚNIOR, R.P. Presença de Xylella fastidiosa em quatro espécies de cigarrinhas da família Cicadellidae coletadas em viveiros de café no Estado do Paraná. In: III SIMPÓSIO DE PESQUISA DOS CAFÉS DO BRASIL, Porto Seguro, 2003. Anais... Brasília: Consórcio Brasileiro de Pesquisa e Desenvolvimento do Café, 2003. v.1, p.349.

PARADELA FILHO, O.; SUGIMORI, M.H.; RIBEIRO, I.J.A.; GARCIA Jr., A.; BERETTA, M.J.G.; HARAKAWA, R.; MACHADO, M.A.; LARANJEIRA, F.F.; RODRIGUES NETO, J.; BERIAM, L.O.S. Primeira constatação em cafeeiro no Brasil da Xylella fastidiosa causadora da clorose variegada dos citros. Laranja, Cordeirópolis, v.16, n.2, p.135-136, 1995.
PARADELA FILHO, O.; SUGIMORI, M.H.; RIBEIRO, I.J.A.; GARCIA Jr., A.; BERETTA, M.J.G.; HARAKAWA, R.; MACHADO, M. A.; LARANJEIRA, F.F.; RODRIGUES NETO, J.; BERIAM, L.O.S. Constatação de Xylella fastidiosa em cafeeiro no Brasil. Summa Phytopathologica, Jaboticabal, v.23, p.4649, 1997.

PURCELL, A.H.; HOPKINS, D.L. Fastidious xylem-limited bacterial plant pathogens. Annual Review of Phytopathology, Palo Alto, v. 34, p.131-151, 1996.

QUEIROZ-VOLTAN, R.B.; PARADELA FILHO, O.; CARELLI, M.L.C.; FAHL, J.I. Aspectos estruturais de cafeeiro infectado com Xylella fastidiosa. Bragantia, Campinas, v.58,n.1,p.23-33, 1998.

QUEIROZ-VOLTAN, R.B.; CABRAL, L.P.; PARADELA FILHO, O. Comparações sazonais do efeito da Xylella fastidiosa em cultivares de cafeeiro. Bragantia, Campinas, v.63, n.3, p.381393, 2004a.

QUEIROZ-VOLTAN, R.B.; CABRAL, L.P.; PARADELA FILHO, O. Severidade do sintoma da bactéria Xylella fastidiosa em cultivares de cafeeiro. Bragantia, Campinas, v.63, n.3, p.395404, 2004b.

QUEIROZ-VOLTAN, R.B.; CABRAL, L.P.; PARADELA FILHO, O.; CARELLI, M.L.C.; FAHL, J.I.; FAZUOLI, L.C. Efeito da Xylella fastidiosa em cafeeiro em diferentes regiões edafoclimáticas. Bragantia, Campinas, v.63, n.1, p.89-100, 2005.

RAMIRO, D.A.; GUERREIRO-FILHO, O.; QUEIROZ-VOLTAN, R.B.; MATTHIESEN, S.C. Caracterização anatômica de folhas de cafeeiros resistentes e susceptíveis ao bicho-mineiro. Bragantia, Campinas, v.63, n.3, p.363-372, 2004.

REDAK, R.A.; PURCELL, A.H.; LOPES, J.R.S.; BLUA, M..; MIZELL III, R.F.; ANDERSON, P.C. The biology of xylemfluid-feeding insect vectors of Xylella fastidiosa and their relation to disease epidemiology. Annual Review Entomology, Palo Alto, v.49, p.243-270, 2004.

SOKAL, R.R.; ROHLF, F.J. Biometry. 2.ed. New York:W. F. Freeman, 1981. 859p.

YORINORI, M.A.; RIBAS, A.F.; UENO, B.; MASSOLA JÚNIOR, N.S. ; LEITE JÚNIOR, R.P. Detecção de Xylella fastidiosa em germoplasma de cafeeiro. Fitopatologia Brasileira, Brasília, v.28, n.4, 2003. 